\title{
Stendhal, Le Rouge et le Noir
}

\section{Michel Arrous}

\section{(2) OpenEdition}

\section{Journals}

\section{Édition électronique}

URL : http://journals.openedition.org/studifrancesi/2189

DOI : 10.4000/studifrancesi.2189

ISSN : 2427-5856

\section{Éditeur}

Rosenberg \& Sellier

\section{Édition imprimée}

Date de publication : 1 avril 2014

Pagination : 157

ISSN : 0039-2944

\section{Référence électronique}

Michel Arrous, «Stendhal, Le Rouge et le Noir », Studi Francesi [En ligne], 172 (LVIII | I) | 2014, mis en ligne le 01 avril 2014, consulté le 18 septembre 2020. URL : http://journals.openedition.org/ studifrancesi/2189; DOI : https://doi.org/10.4000/studifrancesi.2189

\section{Ce document a été généré automatiquement le 18 septembre 2020}

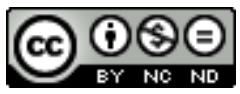

Studi Francesi è distribuita con Licenza Creative Commons Attribuzione - Non commerciale - Non opere derivate 4.0 Internazionale. 


\title{
Stendhal, Le Rouge et le Noir
}

\author{
Michel Arrous
}

\section{RÉFÉRENCE}

STENDHAL, Le Rouge et le Noir, présentation, notes, dossier, chronologie, bibliographie par Marie PARMENTIER, Paris, Flammarion, «GF», 2013, pp. 663.

1 Conformément à la tradition critique qui a privilégié à juste titre le réalisme de la «Chronique de 1830», Marie Parmentier ouvre sa présentation (pp. 7-32) en rappelant l'inscription du roman dans l'histoire et la pertinence du tableau qu'il donne de la configuration sociopolitique de l'époque. Pour autant, ne sont pas négligés, à la suite d'Yves Ansel, les «failles» ou les «angles morts» d'un réalisme stendhalien qui n'est pas aussi monolithique qu'on a pu le dire (p. 15). Il y aurait dans le roman des parties faibles, des échecs (l'épisode de la «note secrète» qui «ne débouche finalement sur rien» - il vaut néanmoins des félicitations à Julien -, la «Chronique de 1830» qui n'aborde pas les Trois Glorieuses). Ces faiblesses signalées, Marie Parmentier, et c'est le point fort de son analyse, s'intéresse à l'inflexion romanesque. Le contexte politique évoqué au filtre d'un réalisme noir serait abandonné au profit de la passion amoureuse ou, plus exactement, le narrateur feint de dissimuler le «virage romanesque» qu'il négocie: «Si le narrateur dénonce les modèles romanesques, c'est en fait un trompel'œil, visant à dissimuler au lecteur que l'intrigue du roman obéit précisément à ce modèle» (p. 19). On retrouve l'argumentation de Marie Parmentier sur la rhétorique manipulatrice de Stendhal (Stendhal stratège, Droz, 2007). Plus convenues sont les pages consacrées à l'écriture stendhalienne, bien que soit opportunément relevée la pratique de la condensation, de l'allusion, et la posture ironique d'un écrivain qui joue avec son lecteur, par exemple dans le choix des épigraphes. À partir du «Projet d'article sur Le Rouge et le Noir» (1832), l'étude de la stratégie de l'écrivain met en évidence une «logique de la distinction» (p. 25) qui est d'ailleurs une véritable éthique. Tout aussi bienvenues, les pages sur la dramatisation du récit et les scènes à suspens (pp. 29-30) 
dans une intrigue «relativement simple», malgré quelques bizarreries et incohérences narratoriales.

2 Le dossier regroupe quatre rubriques: le personnage de Julien Sorel (ses modèles: Rousseau, Napoléon; sa singularité, relevée par les contemporains et revendiquée par Stendhal), le réalisme selon Stendhal (le travail esthétique du romancier qui propose «une compréhension sociologique du monde et des rapports sociaux», récusée par Julien Gracq), la veine romanesque (tension et suspens, imaginaire des personnages et possibles romanesques, relecture romanesque de l'histoire), les rapports entre roman et justice aux $\mathrm{XIX}^{\mathrm{e}}$ et $\mathrm{Xx}^{\mathrm{e}}$ siècles (le pittoresque judiciaire, la rhétorique et le rituel judiciaires illustrés par des exemples tirés de Hugo, Daumier, Camus, Carrère). On regrettera que dans la bibliographie sélective aient été omises des études importantes: d'une part, les articles d'Henriette Bibas (Le Double Dénouement et la Morale du "Rouge", "Revue d'histoire littéraire de la France», 1949), Gérald Rannaud ("Lecture économique» des premiers chapitres du "Rouge et le Noir", in Stendhal, le saint-simonisme et les industriels, 1979), Pierre Laforgue (Une histoire anachronique ou Révolution et décapitation dans "Le Rouge et le Noir", "L'Année Stendhal», 1998; Rouge, noir et bleu. Contribution à une sociocritique du romantisme de 1830 (variation chromatique), "L'Année stendhalienne», 2011); d'autre part, l'ouvrage de Jacques Dubois (Stendhal, une sociologie romanesque, Paris, La Découverte, 2007), et la réédition de celui de Michel Crouzet que Marie Parmentier n'a peut-être pas eu l'occasion de consulter ("Le Rouge et le Noir". Essai sur le romanesque stendhalien suivi de deux essais: La Formation aristocratique de Julien Sorel, La Laideur dans "Le Rouge et le Noir", Paris, Eurédit, novembre 2012). 